\title{
Adaptive Identification of Innovative Production Function of Corporation
}

\author{
Vladimir V. Tsyganov \\ Head Researcher \\ Professor \\ V.A.Trapeznikov \\ Institute of Control Sciences \\ Russian Academy of Sciences \\ Laboratory of Active Systems
}

Cycle of the creation of innovation and its implementation into production is considered for the permanent renewal and development of corporation manufacturing. The hierarchical model of the control system of this cycle is proposed. The result of the functioning of the innovation cycle can be modeled using the innovative production function of corporation. The problem of its adaptive identification is formulated. Sufficient conditions for such identification are obtained taking into account the interests of the elements of the corporation's production system. These conditions are illustrated by the application of adaptive identification of innovative production function with the quadratic losses to wagon-repair production of large-scale corporation Russian Railways.

Keywords: manufacturing, innovation, management, control, adaptation, identification, incentive

\section{INTRODUCTION}

The concept of the new industrial revolution Industry 4.0 was developed with reference to the management of innovations in the manufacturing industry [1]. In the face of competition, innovations support sustainable business development. Technologies and tools developed on the basis of new knowledge and methods of their use should be introduced into production systems. This requires knowledge and technology management in organizations [2]. Recommendations for the implementation of innovative projects within Industry 4.0 were developed in [3]. Cycles of innovation development and their implementation into production should be formed for the permanent renewal and development of manufacturing systems.

Another component of the concept Industry 4.0 is wide use of the elements of artificial intelligence in manufacturing [3]. Cognitive control can be used for the system integration of these elements [4]. This integration includes coordination of different processes deals with innovation and manufacturing.

Cognitive approach is the method of analysis and design based on cognition, the search for interrelationships of events and phenomena. The promising direction of the cognitive approach in relation to the manufacturing system integration is based on a semiotic - the science of "signs" [5].

Designed on the basis of a cognitive approach the logical architecture of innovative production management was discussed in [1]. For example, an innovation management subsystem has been created in the microelectronics manufacturing, integrated into a common management system of corporation [6]. There are separate managers that perform the management func-

Received: March 2019, Accepted: May 2019

Correspondence to: Prof Vladimir Tsyganov

Institute of Control Sciences, Profsoyuznaya 65,

117997, Moscow, Russia

E-mail: bbc@ipu.ru

doi:10.5937/fmet1904691T

(C) Faculty of Mechanical Engineering, Belgrade. All rights reserved tions of production and innovation. Each centre is headed by a manager with the necessary resources. To some extent one can speak of regulation a decentralized corporate management system [7].

To avoid inconsistencies, a coordinator of production and innovation subsystems is appointed at the corporate level. Its functions are related to the organization of an effective cycle of creation of innovation and its implementation [6]. This raises the methodological problem of coordinating 2 heterogeneous subsystems deals with production and innovation. The complexity of this problem determines the relevance of the application of the general theory of systems, cognitive approach and formal modelling, for managing the corporate cycle of innovation development and production.

Cognitive approach to the design of the innovation and production management leads to a specific architecture of the cycle of development and implementation of innovations. Cognitive semiotic framework for manufacturing and innovation systems integration deals with signs which could be linguistic or non-linguistic [8].

Next, the cognitive approach implies the construction and analysis of a cognitive map - a graph, whose vertices correspond to objects (production personnel and management), and the arcs between vertices reflecting the relationship between these objects and the sequence of their actions.

Based on semiotic approach, consider cognitive map of the control organizational structure of cycle of innovation and production management in conditions of uncertainty (Fig. 1). There, at the lower level is production element including personnel realizing technological process (briefly, Element), and at the middle level - production control center (briefly, Center). At the middle level is also the center of innovation development controlling development of new tools and technologies aimed at improving efficiency of production (Fig. 1). At the upper level there is corporation top manager which provides common management (Coordinator). 


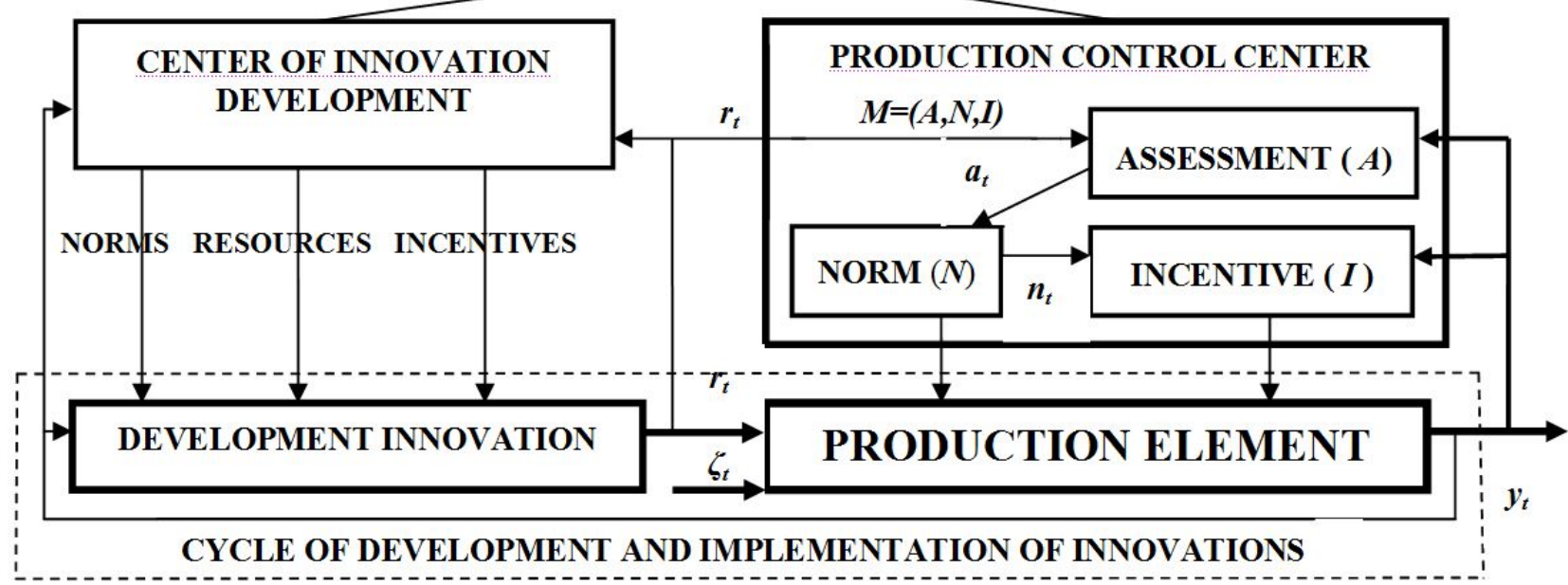

Figure 1. The management structure of the corporative cycle of development and implementation of innovations

The concept of Industry 4.0 is based on the extensive use of elements of artificial intelligence. In conditions of uncertainty, they allow to solve the problems of adaptation [9]. In our case, the Center uses the procedure of adaptive assessment parameters of the cycle of innovation and production management in conditions of uncertainty (A). Based on this procedure, rationing $(\mathrm{N})$ and incentive (I) procedures of production management are formed (Fig. 1). For effective management of this system it is necessary to determine the innovative production function, showing how the resources allocated to innovation affect the performance of a corporation. The objective of the research presented in the paper is mathematical modeling of both an innovative production function and management procedures, which allow to determine the corporation productivity depending on the innovation resource.

\section{INNOVATIVE PRODUCTION FUNCTION}

\subsection{The manufacturing system with innovations}

Consider a two-level production system with innovations, at the upper level of which the Center is located, and at the lower level, the Element, which realizes the process of manufacturing. This system is a part of the management structure of the corporative cycle of development and implementation of innovations shown on Fig. 1.

The output of Element in period $t$ is characterized by value $y_{t}$ (for example, a volume of production), $y_{t} \in R_{+}^{1}$, where $R_{+}^{1}$ is the set of non-negative real numbers, $t=1,2, \ldots$

At the entrance of Element in the period $t$, innovative resource $r_{t}$ is applied (Fig. 1). Suppose that $r_{t}$ is a vector whose components are known to Center, and $r_{t} \in Q_{t} \subset R_{+}^{M}$, where $Q_{t}$ is the closed subset in $M$ dimensional positive affine space $R_{+}^{M}$.

In addition, Element is exposed to accidental factor $\zeta_{t}$ from the environment (Fig. 1) so that:

$$
y_{t} \in Y_{t}\left(p_{t}\right)=\left[0, z_{t}\right], \quad z_{t}=W_{t}\left(p_{t}\right),
$$

$$
p_{t}=\left(\zeta_{t}, r_{t}\right), \quad \zeta_{t} \in \Xi_{t}, \quad p_{t} \in P_{t}=\Xi_{t} \bigcup Q_{t},
$$

where $Y_{t}\left(p_{t}\right)$ is the set of possible outputs, $z_{t}=W_{t}\left(p_{t}\right)$ is the maximal production output (briefly, potential), $\zeta_{t}$ is the random exogenous parameter unknown to Center, $\Xi_{t}$ is the set of possible exogenous parameters, $p_{t}$ is the complex parameter of Element, $P_{t}$ is the set of possible complex parameters of Element, $t=1,2, \ldots$

\subsection{Adaptive identification procedure}

According to (1),(2), the potential $z_{t}=W_{t}\left(\zeta_{t}, r_{t}\right)$ can be considered as stochastic production function which depends on both an innovative resource $r_{t}$ and a accidental realization of the exogenous parameter $\zeta_{t}$. If Center has sufficient statistics of potential $z_{t}$ depending on resource $r_{t}$ then it is possible to use standart regression model [10] to predict mean value of potential $z_{t}$ as a function of resource $r_{t}$. If such statistics are insufficient, appropriate real-time adaptive procedures are usually used for prediction in technical systems [9]. Consider the procedure of adaptive identification of innovative production function in real time.

Suppose that Center observes $r_{t}, z_{t}$ and uses an optimal adaptive algorithm derived in information theory of technical systems identification [11]. Then assuming that the system is functioning in a stationary mode (or normal mode of operation), the assessment of $z_{t}$ in period $t$ is:

$$
\hat{z}_{t}=c_{t-1} q\left(r_{t}\right), \quad t=1,2 \ldots, \quad c_{0}=c^{0},
$$

where $c_{t}$ is a tuned assessment, $q$ is the function of input $r_{t}, q\left(r_{t}\right) \geq 0$. In fact $c_{\mathrm{t}-1} q\left(r_{t}\right)$ is a tuned assessment of the production function of innovative resource $r_{t}$. Center is interested to define this function in order to know how this resource $\left(r_{t}\right)$ will affect the production output $z_{t}$ of a corporation.

Suppose that goal of Center is to minimize the average losses of identification $L(c)=M_{\zeta}\left\{\Phi\left(\varepsilon_{t}\right)\right\}$. There the loss function $\Phi\left(\varepsilon_{t}\right)$ is a convex twice differentiable function of residual $\varepsilon_{t}=z_{t}-\hat{z}_{t}, \Phi(0)=0, M_{\zeta}$ is the expectation operator averaging over all realizations of the random parameter $\zeta_{t}$. 
In accordance with the information theory of identification [11], denote

$$
L_{t}\left(c, z^{t}\right)=\left(\left.\sum_{\tau=1}^{t} \Phi\left(\varepsilon_{\tau}\right)\right|_{c_{\tau-1}=c}\right) / t
$$

the empirical mean losses characterizing the quality of identification, $z^{t}=\left(z_{1}, \ldots, z_{t}\right)^{\prime}$ Denote $\Phi_{c}^{\prime}\left(\varepsilon_{t}\right)$ the derivative of the function $\Phi\left(\varepsilon_{t}\right)$ with respect to $c_{t-1}$. Then the optimal sampling assessment

$$
\begin{aligned}
& \widehat{c}_{t}=\underset{c}{\arg \min } L_{t}\left(c, z^{t}\right)=\widehat{c}_{t-1}-\gamma_{t} \Phi_{c}^{\prime}\left(\varepsilon_{t}\right) \equiv \\
& \equiv A_{t}\left(\widehat{c}_{t-1}, r_{t}, z_{t}\right)
\end{aligned}
$$

There $\gamma_{t}$ is the coefficient chosen so that the $\widehat{c}_{t}$ from (4) converges to the optimal assessment $c *$ :

$$
\begin{aligned}
& \widehat{c}_{t}=\underset{c}{\arg \min _{t}} L_{t}\left(c, z^{t}\right) \underset{t}{\rightarrow} c^{*}=\underset{c}{\arg \min _{c}} L(c) \\
& \gamma_{t} \Phi_{c}^{\prime \prime}\left(\varepsilon_{t}\right)<1, \gamma_{t} \Phi_{c}^{\prime \prime}\left(\varepsilon_{t}\right)<1,
\end{aligned}
$$

where $\Phi_{c}^{\prime \prime}\left(\varepsilon_{t}\right)$ is the second derivative of $\Phi\left(\varepsilon_{t}\right)$ with respect to $c_{t-1}$. By definition, $c^{*} q\left(r_{t}\right)$ is the tuned innovative production function.

\subsection{Problem of the innovative production function identification}

In practice, staff is almost always more informed about innovation production potential than management. In such cases, it is said about the asymmetric awareness of the parties [12]. In this regard, it is necessary to take into account the human factor, or the activity of the parties associated with the desire to use the available information to achieve their own goals [13]. For example Auster analyses the problem of concluding a contract between a fully aware principal and an unaware agent [12]. An introduction to both the literature and the special issue about unawareness has given by Schipper [14].

Based on the hypothesis of asymmetric awareness of the parties, we will assume that Element (that is, employees directly related to manufacturing) is more aware of the frontiers of innovative production than Center (management). Another assumption is that Element (personnel) precisely defines the external conditions, in contrast to the Center (management).

Formally, suppose that the potential $z_{t}$ is unknown to Center, but it becomes known to the staff at the beginning of the production period $t$, i.e. until the choice of output $y_{t}$. So knowing $z_{t}$, the staff can choose the indicator of production $y_{t}$ so as to provide themselves with better assesments and incentives today and in the future. Of course, in any case this output can not exceed the potential: $y_{t} \leq z_{t}$.

Suppose that Element selects an output $y^{*}{ }_{t}$ which is not necessarily equal to the production potential: $y^{*}{ }_{t} \neq z_{t}$ Center observes the innovative resource $r_{t}$ and the output $y^{*}, y^{*}{ }_{t} \leq z_{t}$, and uses the procedure (4) to determine the selective assessment of $a_{t}$ :

$$
\begin{aligned}
& a_{t}=\underset{a}{\arg \min } L_{t}\left(a, y^{t} *\right)=a_{t-1}-\gamma_{t} \Phi_{a}^{\prime}(t) \equiv \\
& \equiv A_{t}\left(a_{t-1}, r_{t}, y_{t}^{*}\right)
\end{aligned}
$$

$$
\begin{aligned}
& \Phi_{a}^{\prime}(t) \equiv \Phi_{a}^{\prime}\left(y_{t}^{*}-\hat{y}_{t}\right), \hat{y}_{t}=a_{t-1} q\left(r_{t}\right), \\
& \gamma_{t} \Phi_{a}^{\prime \prime}(t)<1, t=1,2 \ldots, \quad a_{0}=a^{0},
\end{aligned}
$$

where $\Phi_{a}^{\prime \prime}(t)$ is the second derivative of the function $\Phi(t)$ with respect to $a_{\mathrm{t}-1}$. Then generally speaking, the assessment of $a_{t}$ does not converge to optimal assessment $c^{*}$ because of $y_{t}{ }_{t} \neq z_{t}, t=1,2, \ldots$ Therefore tuned assessment $a_{t-1} q(r)$ does not converge to $c^{*}\left(r_{t}\right)$.

Thus the problem of identification of the production function $c^{*}\left(r_{t}\right)$ arises. This problem concerns not only Center, but also Coordinator, for whom it is important to know how innovation resources $r_{t}$ affect the production of a corporation.

To solve this problem, Center needs to ensure the convergence of the sample assessment $a_{t}$ to the optimal assessment $c^{*}$ :

$$
a_{t}=A_{t}\left(a_{t-1}, r_{t}, y_{t}^{*}\right) \underset{t}{\rightarrow} c^{*}
$$

\section{MOTIVATION OF PRODUCTION PERSONNEL}

\subsection{The problem of disinterest in innovations}

The problem of identification of the production function arises because Center cannot take into account random interference and other factors that become known to production personnel only in the process of innovation implementation. This not only increases risks, costs and time of innovation, but also makes adaptive identification algorithms ineffective.

The problem of identifying a production function $c^{*} q\left(r_{t}\right)$ can be solved by performing (8). Conceptually, it is enough for this to motivate the staff to reveal the production potential in each period: $\mathrm{y}_{\mathrm{t}}{ }^{*}=z_{t}, t=1,2 \ldots$ Indeed, in this case (8) will be satisfied due to (5).

Consider how Center may be interested in the staff in the disclosure of potential, i.e. choosing $\mathrm{y}_{\mathrm{t}}^{*}=z_{t}, t=1,2 \ldots$ Let us refer to the current practice incentive $(I)$ and rationing $(N)$ procedures of production management (Fig. 1).

First, the incentive procedures $(I)$ in production management usually are designed so that incentives grow on the increase in output, compared with the norms (plans). Often stimulation is carried out under the condition of exceeding these norms. Therefore, the higher the norm, the more difficult it is to get a stimulation.

Secondly, the rationing procedure $(N)$ in a large-scale corporation usually is arranged so that norm increased by a certain percentage of the actually achieved output (so called "rationing from the achieved level"). Then the future production norm will be the higher, the higher the performance achieved. Therefore, staff may not be interested in increasing performance above the norm (because the higher the future norm, the harder it is to get a future incentive). Thus, there is a problem of lack of staff interest in the disclosure of production potential.

This problem is exacerbated in the case of innovation, always associated with certain risks, expenses, and costs of time for innovation. For example, the problem of manufacturer's lack of interest in the growth of production is key to the introduction of innovations in microelectronics [6]. Thus the problem of personnel lack of interest in disclosing productive potential when 
"rationing from the achieved level" creates the problem of disinterest in innovations. So to identify the production function $c^{*} q\left(r_{t}\right)$ it is necessary to select rationing $(N)$ and incentive $(I)$ procedures of management in such a way as to motivate staff to unleash the potential of production.

\subsection{The rationing and incentive procedures}

Consider the following order of operation of the production system with innovations in the period $t$, $t=1,2 \ldots$ At the beginning of this period, Center and Element become aware of the vector $r_{t}$. Based on the assessment $a_{i-1}$ in the previous period determined by (6),(7), Center assigns norm to Element for the period $t$ :

$$
n_{t}=N\left(a_{t-1}\right) \in R^{1}, N\left(a_{t-1}\right) \uparrow a_{t-1},
$$

where $N\left(a_{t-1}\right)$ is the rationing procedure, $t=1,2 \ldots$

Further, Element becomes aware of the specific value of the random parameter $\zeta_{t}$ in period $t$. Thus, he becomes known parameter $p_{i}$. Based on this, Element chooses the output $y_{t} \in Y_{t}\left(p_{t}\right)$.

Then, depending on the implementation of the norm $n_{t}$, Center determines he incentive for Element:

$$
\phi_{t}=I\left(n_{t}, y_{t}\right) \in R^{1}, I\left(n_{t}, y_{t}\right) \uparrow y_{t}, I\left(n_{t}, y_{t}\right) \downarrow n_{t},
$$

where $I\left(n_{t}, y_{t}\right)$ is the incentive procedure, $t=1,2 \ldots$. In addition Center, based on a known $r_{t}$ and observed $y_{t}$ generates assessment $a_{i}$ in period $t$ using a recurrent identification procedure (6), (7).

A set of identification procedures (6), (7), rationing (9) and incentive (10) is called the adaptive mechanism of the innovative production system (briefly, adaptive mechanism) and denoted $M=(A, N, I)$ (Fig. 1). Similar adaptive mechanisms are used for a sustainable development of organizations [15].

The above determines the relevance of designing an adaptive mechanism $M=(A, N, I)$, which would ensure the production staff's desire both to unlock the potential and to identify the production function. Accordingly, this would make it possible take all the opportunities of innovation implementation.

\subsection{Element choice}

Suppose that Element seeks to increase the amount of discounted incentives:

$$
V_{t}=\sum_{\tau=t}^{t+T} \rho^{\tau-t} \varphi_{\tau}, \quad 0<\rho<1,
$$

where $\rho$ is the discount factor, $T$ is Element foresight. In this case, Element well Center knows only the possible future sets of parameters $P_{t}$ and outputs $Y_{\tau}\left(p_{t}\right)$, $\tau=\overline{t+1, t+T}$. To make a decision about outputs $y_{t}$ on the conditions of uncertainty Element focuses on the guaranteed value of the goal function (11):

$$
w_{t}\left(n_{t}, y_{t}\right)=\min _{p_{\tau} \in P_{\tau}, \quad \tau=\overline{t+1, t+T}} \min _{y_{\tau} \in Y_{\tau}\left(p_{\tau}\right), \tau=\overline{t+1, t+T}} V_{t} .
$$

Then the set of Element possible choices is the set of outputs $y_{t}$ that maximize (12):

$$
\begin{aligned}
& R_{t}\left(M, p_{t}\right)=\left\{y_{t}^{*} \in Y\left(p_{t}\right) \mid w_{t}\left(n_{t}, y_{t}^{*}\right) \geq\right. \\
& \left.\geq w_{t}\left(n_{t}, y_{t}\right), y_{t} \in Y_{t}\left(p_{t}\right)\right\} .
\end{aligned}
$$

We will assume that the hypothesis of benevolence of Element with respect to Center is valid: if $z_{t} \in R_{t}\left(M, p_{t}\right)$, then $y_{t}^{*}=z_{t}, t=1,2, \ldots$ It means that Element does not underassessment its output if it is not profitable for it.

\section{CONDITIONS OF INNOVATIVE PRODUCTION FUNCTION IDENTIFICATION}

Element selects an output $y_{t}{ }_{t}$ from the set of choices $R_{t}\left(M, p_{t}\right)$. Then generally speaking $y^{*} \neq z_{t}$ according to (13). So assessment $a_{t}$ (6) does not converge to the optimal assessment $c^{*}$. Thus to solve the problem of adaptive identification of the production function (8) it is nesessary:

$$
a_{t}=A_{t}\left(a_{t-1}, r_{t}, y_{t}^{*}\right) \underset{t}{\rightarrow} c^{*}, y_{t}^{*} \in R_{t}\left(M, p_{t}\right) .
$$

Consider the solution of this problem based on the principle of the guaranteed result. For each period $t$, $t=1,2, \ldots$, we introduce operator to eliminate uncertainty in relation to the parameters and outputs preceding the choice of $y_{t}$ :

$$
g_{t} u=\min _{p_{t} \in P_{t}} \min _{p_{t-1} \in P_{t-1}} \min _{y_{t-1} \in Y_{t-1}\left(p_{t-1}\right)} \ldots \min _{p_{1} \in P_{1}} \min _{y_{1} \in Y_{1}\left(p_{1}\right)} \frac{\partial}{\partial u} .
$$

The uncertainty elimination operators with respect to the parameters and outputs after selecting $y_{t}$ is introduced:

$$
\begin{aligned}
& d_{t} u=\min _{\tau=t+1, t+T} \min _{p_{t+1} \in P_{t+1}} \min _{y_{t+1} \in Y_{t+1}\left(p_{t+1}\right)} \cdots \\
& \ldots \min _{p_{\tau} \in P_{\tau}} \min _{y_{\tau} \in Y_{\tau}\left(p_{\tau}\right)} \frac{\partial}{\partial u} .
\end{aligned}
$$

Assuming the differentiability of functions $N\left(a_{t-1}\right)$ and $I\left(x_{t}, y_{t}\right)$ we denote:

$$
\begin{gathered}
F_{t}=d_{t} n_{\tau} \varphi_{\tau}, \quad G_{t}=g_{t} y_{t}\left[-\Phi_{a}^{\prime}(t)\right], \\
H_{t}=d_{t} a_{\tau-1} \Phi_{a}^{\prime}(\tau), \quad J_{t}=d_{t} a_{\tau-1}\left(-n_{\tau}\right) .
\end{gathered}
$$

Theorem. For identification the innovative production function it is sufficient to use adaptive mechanism $M=(A, N, I)$, which procedures satisfying the enequality:

$$
\begin{aligned}
g_{t} y_{t} \varphi_{t}+\rho \gamma_{t} F_{t} G_{t} J_{t}\left[1-\rho^{T}\left(1-\gamma_{t} H_{t}\right)^{T}\right] / \\
/\left[1-\rho\left(1-\gamma_{t} H_{t}\right)\right] \geq 0, \quad t=1,2, \ldots
\end{aligned}
$$

Proof of Theorem is given in Appendix.

Note that the approach used in the formulation and proof of the Theorem is also applicable to unlock the potential and to identify the innovative production function with similar recurrent algorithms of adaptive identification tested in technical systems [11].

\section{EXAMPLE: RAILWAY WAGON-REPAIR PRODU- CTION}

Applications of adaptive mechanism $M=(A, N, I)$ that satisfy the conditions of the Theorem are aimed at using 
the production potential and identification innovative production function. We shall illustrate such application on the example of the wagon-repair production with innovations in the large-scale corporation Russian Railways (briefly, Corporation).

\subsection{Innovations in wagon-repair production}

Corporation has created the hierarchical system of wagon-repair production as the service support structure [16]. The corresponding hierarchical production system with innovations is shown in Fig.1.

The role of the production control center is played by the corporation's wagon-repair production regulation department (briefly, Department). It controls the actual volume of the production - the number $y_{t}$ of wagons released after an overhaul which characterizing the efficiency of wagon-repairing in period $t$.

In order to remain competitive in the conditions of changes, management of Corporation must implement innovations in wagon-repair production. To make informed decisions about innovation, it needs to know how their quantity and quality will affect production performance. For this management must identify wagon-repair production function with innovations.

Then it is necessary to take into account the human factor or the activity of production element - the wagonrepair enterprise that is affected by a random factor $\zeta_{t}$. In the condition of uncertainty Department uses the procedures of identification $(A)$, rationing $(N)$ and incentive (I) to improve the production efficiency of the enterprise and to identify innovative production function.

\subsection{Linear identification procedure}

Let the loss function of identification is quadratic: $\Phi(t)=\left(y_{t}-\hat{y}_{t}\right)^{2} / 2$. So according to (6) the identification procedure is linear

$$
\begin{aligned}
& a_{t}=A_{t}^{l}\left(a_{t-1}, r_{t}, y_{t}\right)=\left[1-\gamma_{t} q^{2}\left(r_{t}\right)\right] a_{t-1}+ \\
& +\gamma_{t} q\left(r_{t}\right) y_{t}, a_{0}=a^{0}, 0<\gamma_{t} q^{2}\left(r_{t}\right)<1, t=1,2, \ldots
\end{aligned}
$$

Suppose that the rationing procedure (9) is also linear:

$$
n_{t}=N^{l}\left(a_{t-1}\right)=k a_{t-1} q\left(r_{t}\right), \quad k>0, \quad t=1,2, \ldots,
$$

where $k$ is the growth rate. Note procedure (20), formed on the basis of an adaptive procedure (19) is in fact procedure of "rationing from the achieved level". Such procedures are used for the sustainable development of large-scale corporations in the face of uncertainty [15].

It is not difficult to show that at (19) and (20) condition (18) takes the form:

$$
\begin{aligned}
& k \leq g_{t} y_{t} \phi_{t}\left[1-\rho\left(1-\gamma_{t} \underline{h}_{t}\right)\right] / \rho \gamma_{t} \underline{q}_{t}\left(-F_{t}\right)\left[1-\rho^{T}(1-\right. \\
& \left.\left.-\gamma_{t} \underline{h}_{t}\right)^{T}\right], t=1,2, \ldots \\
& \quad \underline{q}_{t}=\min _{r_{t} \in Q_{t}} q\left(r_{t}\right), \underline{h}_{t}=\min _{r_{\tau} \in Q_{\tau}, \tau=t+1, t+T} q^{2}\left(r_{\tau}\right) .
\end{aligned}
$$

Thus, the theorem establishes restrictions from above on the growth rate $k$, in the form of inequality (21). The right side of this inequality depends on incentive procedure (10). Suppose that the stimulation procedure (10) is linear:

$$
I\left(n_{t}, y_{t}\right)=s\left(y_{t}-n_{t}\right)+\text { const }, \quad s>0 .
$$

Then, taking (14) - (16) into account, we obtain that condition (22) takes the form:

$$
\begin{aligned}
& k \leq\left[I-\rho\left(1-\gamma_{t} \underline{h}_{t}\right)\right] / \\
& / \rho \gamma_{t} \underline{q}_{t}\left[1-\rho^{T}\left(1-\gamma_{t} \underline{h}_{t}\right)^{T}\right], t=1,2, \ldots
\end{aligned}
$$

Thus, for using the production potential and identification of innovation production function it is sufficient to select linear procedures of identification (19), rationing (20), and stimulating (23), that satisfies condition (24).

Using (19)-(24), Department can calculate the parameters, norms and incentives, knowing the numerical values of $a^{0}, r_{t}, s$ and using the coefficients $\gamma_{t}$ from the appropriate identification algorithm [11]. We do not give here examples of practical calculations on the base of data from the real case study of wagon-repair prouction using formulas (19) - (24), because of their cumersomeness, as well as the obviousness of their results, which fully correspond to the theoretical principles stated above.

Let us consider the important case of smallness of the parameter $\gamma_{t} q^{2}\left(r_{t}\right)<<1, t=1,2, \ldots$ This is possible in particular with a small gain factor $\gamma_{t}$, a lack of resource $r_{t}$ or inefficient use of it (i.e. smallness of the function $\left.q\left(r_{t}\right)\right)$. If this parameter tends to zero: $\gamma_{t} q^{2}\left(r_{t}\right) \rightarrow 0, t=$ $1,2, \ldots$, then by definition in (22) $\gamma_{t} \underline{h}_{t} \rightarrow 0$. In the limiting case, putting in (21) $\gamma_{t} \underline{h}_{t}=0$, we obtain:

$$
k \leq(1-\rho) /\left[\rho \gamma_{t} \underline{q}_{t}\left(1-\rho^{T}\right)\right], \quad t=1,2, \ldots
$$

Thus for using the production potential and identification of innovation production function it is sufficient to select $A^{l}, N^{l}, I^{l}$ that satisfies simple condition (25).

This example illustrates the simplicity and transparency of the linear adaptive mechanism $M^{l}=\left(A^{l}\right.$, $N^{l}, I^{l}$ ) with the linear procedures of identification (19), rationing (20), and incentive (23), as well as the practical applicability of the developed condition (18) of Theorem.

\section{DISCUSSION}

In practice the linear adaptive mechanism $M^{l}=\left(A^{l}, N^{l}\right.$, $\left.I^{l}\right)$ used for simplicity and transparency. First, the fulfillment of conditions (24) or (25) ensures the achievement of such goals of Center and Coordinator as the maximum production volume with innovations and the definition of a production function. The developed approach allows Center to use an efficient adaptive identification algorithm in technical systems (19).

Secondly, due to the selection of procedures of rationing (20) and incentive (23), production personnel are interested in increasing production and introducing innovations. In principle, this can be achieved without special additional incentives for introducing innovations. Such procedures interest production personnel 
also in reducing risks, costs, and time of innovation. Without this effective implementation of innovations is impossible, and their creation loses its meaning.

Generally, Theorem creates the possibility for the implementation of an adaptive mechanism $M=(A, N, I)$ ensuring the aspiration of the personnel of the enterprise to show the corporation's true production function with full use of innovative tools and technologies.

Namely, if condition (18) is fulfilled, the guaranteed value of the goal function of Element (i.e. discounted enterprize personnel incentives) increases with an increase its output. Thus, under the conditions of the Theorem production personnel are interested in increasing its output to the maximum achievable level. This provides the ability for Center to obtain the best assesment (1) of the production potential and to identify innovative production function $c^{*} q\left(r_{t}\right)$. So the interests of Element, Center, and Coordinator are harmonized.

Conditions (18) are constructive, directly limiting the parameters of adaptive procedure $A$, rationing procedure $N$, and incentives procedure $I$. For example, given the assessment procedure and incentives, these conditions impose concrete restrictions on the rationing procedure $N$. Namely, condition (22) implies limited growth of norms with an increase of production. Otherwise, if the rate of growth of the norm "from the achieved level" is too high, the interest of the personnel in the development of potential is lost. Thus Center should set up intense norms which however should not grow too quickly with the success of personnel.

Further, given the adaptive and rationing procedures, condition (18) requires guaranteed growth rates of incentives with increasing wagon-repair efficiency. Substantially, the growth of the current production personnel incentive for good work today should cover the losses from the reduction of future incentives when "rationing from the achieved level".

\section{CONCLUSION}

For continuous updating and development of production in the large-scale corporation, the cycle of designing the innovation and their introduction into manufacturing is needed. This raises the problem of coordinating heterogeneous subsystems of production and innovation. The complexity of this problem determines the relevance of investigation of the control system of innovative production. For this we consider innovative production function which allows to determine the performance of the manufacturing as a function of the innovation resource.

Accounting for the human factor shows that the problem of this function identification is related to the problem of disclosure of production potential. To solve this problem, we proposed approach based on adaptive mechanisms of management that motivate production personnel to increase production and disclosure of potential.

We obtain sufficient conditions for adaptive identification of innovative production function. They are constructive and allow us to assess the production output with innovations, using a variety of adaptive identification algorithms in technical systems. Then the result of the coordinated functioning of the corporative cycle of creation of innovation and its implementation into production can be modelled using the innovative production function. Note that as an argument, in this function, we can use both value and natural indicators of innovation resources.

In principle, the motivation production personnel in increasing production and reducing the risks, costs and time of innovation can be achieved without additional incentives for introducing innovations.

The considered practical example show that the innovative production function can be an effective tool to simulate results of the corporative cycle. Its adaptive identification can support the decision making in a large-scale corporation production with innovations under conditions of uncertainty. In practice, managers in such a corporation perform various combinations of the above basic functions $A, N, I$. Thus it is possible to design more and more complex decision support systems in innovative production management. Possible future research in this area is related to the design of complex adaptive identification models as effective innovative tools for processing big data about production with innovations in large-scale corporations.

Notice that we based our investigation on two key assumptions concerning human factor. The essence of one of them is that Element (that is, personnel directly linked to production) is much more aware of production frontiers than Center (management). Another assumption is that Element (personnel) identifies the exogenous conditions with certainty, unlike the Center (management), which is not capable of it, and forced resort to adaptive identification. Both these assumptions are important in particular in the case of the wagon repair. However we are far from being generalizable these assumptions to every contexts of innovation imlementation into manufacturing.

Of course the considered adaptive identification models and mechanisms, based on the management of expectations and assessments, incentives and stimuli, is not enough for the introduction of innovations. Other widely recognized fundamental aspects are extremely important, such as the organizational, learning, and knowledge dimensions. Having in mind that these dimensions are fundamental, more comprehensive formal approaches to adaptive innovation management should be developed.

\section{APPENDIX: PROOF OF THE THEOREM}

Differentiating according to (11), we obtain:

$$
\frac{\partial V_{t}}{\partial y_{t}}=\frac{\partial \varphi_{t}}{\partial y_{t}}+\sum_{\tau=t+1}^{t+T} \rho^{\tau-t} \frac{\partial \varphi_{\tau}}{\partial n_{\tau}} \frac{\partial n_{\tau}}{\partial a_{\tau-1}} \frac{\partial a_{\tau-1}}{\partial y_{t}}
$$

Substituting the expression for $a_{t}$ from (6) into (26), and using (26) as recurrent relation, we obtain:

$$
\begin{array}{r}
\frac{\partial V_{t}}{\partial y_{t}}=\frac{\partial \varphi_{t}}{\partial y_{t}}-\gamma_{t} \frac{\partial \Phi_{a}^{\prime}(t)}{\partial y_{t}} \sum_{\tau=t+1}^{t+T} \rho^{\tau-t} \frac{\partial \varphi_{\tau}}{\partial n_{\tau}} \frac{\partial n_{\tau}}{\partial a_{\tau-1}} \bullet \\
\bullet \prod_{\zeta=t+1}^{\tau-1}\left[1-\gamma_{\zeta} \Phi_{a}^{\prime \prime}(\zeta)\right] .
\end{array}
$$


Consider the signs of terms (27). According to (10), the first term is $\partial \varphi_{t} / \partial \gamma_{t} \geq 0$. Its minimum value, for any valid preceding outputs $y_{\mu} \in Y_{\mu}\left(p_{\mu}\right)$ and parameters $p_{\mu} \in P_{\mu}, \mu=\overline{1, t-1}$, according to (14), is equal to $g_{t} y_{t} \varphi_{t}$ :

$$
\partial \varphi_{t} / \partial y_{t} \geq g_{t} y_{t} \varphi_{t}
$$

Let determine the sign and the upper assessment of the deductible in (27). According to (5) $\gamma_{t}>0$. Further, $\Phi\left(y_{t}-\hat{z}_{t}\right)$ is a convex twice differentiable function that grows with an increase in the residual $\varepsilon_{t}=y_{t}-\hat{z}_{t}$. Therefore $\Phi_{a}^{\prime}\left(y_{t}-\hat{z}_{t}\right)$ monotonously decreases with growth of $y_{t}$ so $\frac{\partial \Phi_{a}^{\prime}(t)}{\partial y_{t}} \leq 0$. By virtue of $\partial n_{\tau} / \partial a_{\tau-1} \geq 0$, and by virtue of (10) $\partial \varphi_{t} / \partial n_{t} \leq 0$. From inequality (7) it follows that all the factors under the sign of the product are positive. Taking into account the signs of all factors of the deductible in (27), we obtain that the deductible in (27) is also positive.

Hence, using the definitions (14)-(17) and condition $\gamma_{t} \geq \gamma_{t+1}$ from (5), it is easy to show that both for any valid previous outputs $y_{\mu} \in Y_{\mu}\left(p_{\mu}\right), \mu=\overline{1, t-1}$, and parameters $p_{\eta} \in P_{\eta}, \eta=\overline{1, t}$, and for future outputs $y_{l} \in Y_{l}\left(p_{l}\right)$ and parameters $p_{l} \in P_{l}, l=\overline{t+1, t+T}$, the next inequality holds true:

$$
\begin{aligned}
& \gamma_{t} \frac{\partial \Phi_{a}^{\prime}(t)}{\partial y_{t}} \sum_{\tau=t+1}^{t+T} \rho^{\tau-t} \frac{\partial \phi_{\tau}}{\partial n_{\tau}} \frac{\partial n_{\tau}}{\partial a_{\tau-1}} \prod_{\zeta=t+1}^{\tau-1}\left[1-\gamma_{\zeta} \Phi_{a}^{\prime \prime}(\zeta)\right] \leq \\
& \leq \rho \gamma_{t} F_{t} G_{t} J_{t} \frac{1-\left[\rho\left(1-\gamma_{t} H_{t}\right)\right]^{T}}{\left[1-\rho\left(1-\gamma_{t} H_{t}\right)\right]} .
\end{aligned}
$$

Subtracting (29) from (28) and taking into account (27) we obtain:

$$
\begin{gathered}
\partial V_{t} / \partial y_{t} \geq g_{t} y_{t} \varphi_{t}+\rho \gamma_{t} F_{t} G_{t} J_{t}[1- \\
\left.-\rho^{T}\left(1-\gamma_{t} H_{t}\right)^{T}\right] /\left[1-\rho\left(1-\gamma_{t} H_{t}\right)\right], \quad t=1,2, \ldots
\end{gathered}
$$

Then $\partial V_{t} / \partial \gamma_{t} \geq 0$ according to the condition of the Theorem (18). So $V_{t}$ is a non-decreasing function $y_{t}$ with any preceding and future admissible outputs and parameters. Thus according to (12) the maximum $w_{t}\left(n_{t}, y_{t}\right)$ is reached at $y_{t}=z_{t}$. Then in accordance with (13) $z_{t} \in R_{t}\left(M, p_{t}\right)$. From here, by virtue of the hypothesis of Element benevolence with respect to Center, we have $y_{t}{ }_{t}=z_{t}, t=1,2, \ldots$, and the identification condition (8) takes place, Q.E.D.

\section{ACKNOWLEDGMENT}

This work is partially sponsored by grant № 17-2005216 given by Russian Foundation for Basic Research and corporation Russian Railways.

\section{REFERENCES}

[1] Bauernhansl, T., Hompel, M. and Vogel-Heuser, B.: Industrie 4.0 in produktion, automatisierung und logistik - anwendung, technologie, migration, Wiesbaden, Springer, 2014.

[2] Putnik, G.D., Cruz-Cunha, M.M.: Knowledge and technology management in virtual organizations: issues, trends, opportunities and solutions, IGI Global, Hershey, 2007.

[3] Kagermann, H., et al.: Recommendations for implementing the strategic initiative Industry 4.0, in: Abschlussbericht des arbeitskreises Industrie 4.0, DAT, Frankfurt/Main, pp. 5-105, 2013.

[4] Blanchet, M., Rinn, T., Thaden, G. Thieulloy, G.: Industry 4.0 - the new industrial revolution. How Europe will succeed, Roland Berger Strategy Consultants GMBH, München, 2014.

[5] Putnik, G.D.: Semiotics-based manufacturing system integration, Int. J. of Computer Integrated Manufacturing, Vol. 23, No. 8, pp. 687-690, 2010.

[6] Shishkin, G., Tsyganov, V.: Mechanism of adaptation of microelectronics manufacturing to market, in: The Experience of Designing and Application of CAD Systems in Microelectronics - Proceedings of the 6th Conference CADSM 2001, 0103.02.2001, Lvov, pp. 119-120.

[7] Tsyganov, V.: Regulation of decentralized active system development and intelligent control mechanisms, IFAC-PapersOnline, Vol. 9 , No. 3, pp. 9498, 2010.

[8] Putnik, G.D., Putnik Z.: A semiotic framework for manufacturing systems integration - Part I: Generative integration model, International J. of Computer Integrated Manufacturing, Vol. 23, No. 8, pp. 691-709, 2010.

[9] Susai, M. J, Sai Balaji, M. A., Dinakaran D.: Prediction and geometric adaptive control of surface roughness in drilling process, FME Transaction, Vol. 47, No. 3, pp. 424-429, 2019.

[10]Rusov, J., Misita, M., Milanovic, D.D., Milanovic, D.Lj.: Applying regression models to predict business results, FME Transaction, Vol. 45, No. 4, pp. 198-202, 2017.

[11] Tsypkin, J.: Fundamentals of information theory of identification, Nauka, Moscow, 1984 (in Russian).

[12] Auster, S.: Asymmetric awareness and moral hazard, Games and Economic Behavior, Vol. 82, pp. 503-521.

[13] Burkov, V., Gubko, M., Kondratiev, V., Korgin, N. Novikov D.: Mechanism design and management. Mathematical methods for smart organizations, NOVA Publishers, New York, 2013.

[14] Schipper, B. C.: Unawareness - a gentle introduction to both the literature and the special issue, Mathematical Social Sciences, Vol. 70, pp. 1-9.

[15] Borodin, D., Gurlev, I., Klukvin, A., Tsyganov, V.: Adaptive mechanism for sustainable development, Systems Science, Vol. 30, No. 2, pp. 89-95, 2004.

[16] Enaleev, A., Tsyganov, V.: Service support structure optimization of a large-scale rail company, CEUR Workshop Proceedings, Vol.. 2098, pp. 396406, 2018. 


\section{АДАПТИВНА ИДЕНТИФИКАЦИЈА ИНОВАТИВНЕ ПРОИЗВОДНЕ ФУНКЦИЈЕ КОРПОРАЦИЈЕ}

\section{Владимир В. Циганов}

У раду се разматра циклус креирања иновација и њених имплементација у производњу за континуирану „реиновацију“ и развој производње једне корпорације. Предложен је хијерархијски модел система контроле овог циклуса. Резултат функцио- нисања иновационог циклуса може се моделирати коришћењем функције иновативне производње корпорације. Формулисан је проблем његове адаптивне идентификације. Довољни услови за такву идентификацију се добијају узимајући у обзир интересе елемената производног система корпорације. Ови услови су илустровани применом адаптивне идентификације функције иновативне производње са квадратним губицима за ремонтну производњу вагона корпорације великих скала Руске железнице. 